\title{
A audição da criança na tomada de decisão dos magistrados
}

\section{Children's participation in the magistrate's decision-making}

\author{
Maria de Fátima Melo e Ana Isabel Sani ${ }^{\mathrm{b}}$ \\ ${ }^{\mathrm{a} P o r t o,}$ Portugal ${ }^{\mathrm{b}}$ Universidade Fernando Pessoa, Porto, Portugal
}

Resumo: Apresenta-se um estudo qualitativo que pretende analisar a importância que os magistrados atribuem à audição de crianças e jovens envolvidos em processos judiciais e a sua influência na tomada de decisão. Para o estudo constituiu-se uma amostra intencional de 12 magistrados com experiência profissional em Tribunais de Família e Menores, com idades entre os 43 e os 62 anos e de ambos sexos. A recolha de dados foi feita através de entrevista, tendo sido elaborado um guião semiestruturado e semidiretivo, previamente testado. As entrevistas duraram em média vinte minutos, sendo gravadas mediante consentimento informado e depois transcritas para análise de conteúdo. Os resultados revelam que a maior parte dos magistrados dá importância à audição das crianças, realçando os documentos nacionais e internacionais. A amostra admite que o critério primordial no qual baseiam a decisão judicial é o superior interesse da criança. Alguns elementos da amostra reconhecem que o que mais influencia a tomada de decisão é a opinião da criança e a perspetiva desta sobre as suas vivências quotidianas. Desta forma, é da responsabilidade dos magistrados a abertura necessária para que as vozes das crianças sejam valorizadas.

Palavras-chave: crianças, magistrados, audição, tomada de decisão judicial.
Abstract: This is a qualitative study which aims at analyzing the importance magistrates give to the hearings of children and young people involved in lawsuits, as well as the way these influence their decision-making. For this study, an intentional sample of 12 male and female magistrates with experience in Juvenile and Family Courts was gathered, aged between 43 and 62 . Data collection was done through interviews, for which a previously tested interview script (semistructured and semi-directive) was designed. The interviews lasted twenty minutes on average, and were recorded and transcribed for content analysis, after the interviewees' due consent. The results reveal that most magistrates value these hearings, giving emphasis to national and international documents. The subjects of this sample admit that the prevailing criterion for decisionmaking is the best interest of the child and the latter's perspective on daily experience. Thus, it is ultimately the magistrates' responsibility to make the child's voice be heard and valued.

Keywords: children, magistrates, hearings, judicial decision-making.

Contacto: A. I. Sani. Faculdade de Ciência Humanas e Sociais da Universidade Fernando Pessoa, Praça 9 de abril, 349, 4029-004, Porto, Portugal. Correo electrónico: anasani@ufp.edu.pt

Cómo citar: Melo, M. F. y Sani, A. I. (2015). A audição da criança na tomada de decisão dos magistrados. Revista de Psicología, 24(1), 1-19. http://dx.doi.org/10.5354/0719-0581.2015.37067 


\section{Introdução}

A Convenção dos Direitos das Crianças (CDC) é um importante instrumento jurídico que clarifica os direitos das crianças no nível internacional (Fundo das Nações Unidas para a Infância, Unicef, 2004), tendo sido ratificado por Portugal em 1990. A CDC proporcionou assim um conjunto de modificações fundamentais no âmbito jurídico e legislativo de cada país que a ratificou, alterando radicalmente a conceção de criança e tornando possível a valorização destas enquanto atores sociais (Tomás, 2011). Este documento integra um conjunto de artigos que salvaguardam direitos de provisão, proteção e participação e implementam a conceção da criança como um sujeito de direitos (Fernandes, 2009).

Há dois artigos neste instrumento jurídico que é importante dar relevo. No artigo $12^{\circ}$ da Convenção é determinado o direito da criança a ser ouvida e a expressar a sua opinião, tendo em consideração a sua idade e maturidade, devendo ser "assegurada à criança a oportunidade de ser ouvida nos processos judiciais e administrativos" (Unicef, 2004, p. 10). No artigo $3^{\circ}$ é contemplado o superior interesse da criança ao afirmar que "todas as decisões relativas a crianças, adotadas por instituições públicas ou privadas de proteção social, por tribunais, autoridades administrativas ou órgãos legislativos, terão primacialmente em conta o interesse superior da criança" (Unicef, 2004, p. 6). Este critério ressalta que, em caso de conflito de interesses, o direito do superior interesse da criança deve prevalecer sobre os restantes (Couso, 2006; Carvallo, 2008; Guerrero, 2002). Segundo Guerrero (2002), o interesse superior da criança é um conceito jurídico indeterminado, porque se refere "a realidades que englobam um número de hipotéticos casos, de tal forma que a norma não pode precisar a priori o modo de proceder em cada um" (p. 89). Na perspetiva de Bruñol (1999), este critério só será alcançado se houver a satisfação dos direitos da criança. Por conseguinte, a aplicação deste conceito, principalmente no sistema jurídico, passa pela análise dos direitos que estão a ser afetados até ao momento e os que poderão ser atingidos aquando da decisão judiciária. Assim, estes dois artigos são complementares, visto que o artigo $3^{\circ}$ institui a finalidade de alcançar os melhores interesses da criança, enquanto o artigo $12^{\circ}$ constitui um dos meios pelo qual a determinação desse superior interesse é atingida. $\mathrm{O}$ artigo $3^{\circ}$ só será implementado se o artigo $12^{\circ}$ for tomado em consideração (Lansdown, 2011). Portanto, os dois artigos fazem antever que "a partir do interesse da criança, a consideração da sua participação implica que a sua voz seja integrada nos processos de tomada de decisão nos assuntos que lhe dizem respeito" (Cunha \& Fernandes, 2012, p. 38).

Na Europa, há também grande preocupação em criar sistemas de justiça ajustados à condição específica das crianças, integrando os direitos, os interesses e as necessidades tão aclamados a nível internacional. Assim, em 1996 surge a Convenção Europeia sobre o Exercício dos Direitos das Crianças (CEEDC), adotada e ratificada em Portugal apenas a 1 de Julho de 2000. Este instrumento chama a atenção para os direitos e o superior interesse das crianças serem valorizados e promovidos nos processos de família que lhe digam respeito e explicita qual o papel dos intervenientes (e.g., autoridades judicias, representantes) no decurso desses processos para o melhor exercício dos direitos dos mais novos. A Convenção estipula (artigos 6 a 9) que compete às autoridades judiciais a disposição ou a obtenção de informação suficiente e rele- 
vante para a tomada de decisão; a escuta e consideração das opiniões expressas pela criança, assegurando que estas receberam a informação pertinente; o dever de agir de forma eficiente, de modo a prevenir atrasos; a ação por iniciativa própria e a nomeação de um representante, caso haja um conflito de interesses entre a criança e os representantes legais (Gabinete de Documentação e Direito Comparado, s. d.). Já os representantes têm o dever de informar a criança sobre questões relevantes; explicitar quais as consequências de agir em conformidade com a opinião desta, se considerar que a criança tem entendimento para tal e averiguar a sua opinião, a fim de a poder transmitir à autoridade judicial (Gabinete de Documentação e Direito Comparado, s. d.).

Em 2010 foi concebido outro documento com um conjunto diretrizes referentes à justiça adaptada às crianças pelo Comité de Ministros do Conselho da Europa com a finalidade de garantir todos os direitos da criança em qualquer processo e colmatar os obstáculos que estas enfrentam quando se veem envolvidas no sistema de justiça (Conselho da Europa, 2013). As crianças deparam-se com "ambientes intimidatórios, falta de informação e de explicações adequadas à idade, fraca abordagem em relação à família, bem como processos que ora são demasiado longos ora, pelo contrário, são demasiado expeditos" (Conselho da Europa, 2013, p. 7), o que leva os Estados a repensar e examinar as lacunas e os problemas existentes nos seus sistemas de justiça e implementar princípios, direitos e práticas judiciais mais amigas das crianças (Conselho da Europa, 2013).

Portugal, a partir da ratificação dos instrumentos jurídicos enunciados anteriormente, trabalhou no desenvolvimento de legislação que fosse ao encontro dos ide- ais destes. Da reforma surgiram dois principais diplomas a nível nacional na área infantojuvenil, a Lei de Proteção de Crianças e Jovens em Perigo (LPCJP) (Lei No147/99, de 1 de Setembro) e Lei Tutelar Educativa (LTE) (Lei $N^{\circ}$ 166/99, de 14 de Setembro), que promovem os direitos das crianças e garantem a sua proteção, acautelando o direito de participação nos processos judiciais. Portanto, no âmbito do sistema de justiça portuguesa, as crianças e os jovens têm o direito da palavra e da expressão da sua vontade, oferecendo uma participação cada vez mais ativa nos processos judiciais que lhe dizem respeito, pelo menos teórica e simbolicamente (Tomás, 2011), pois este direito pode não passar apenas do papel, ou seja, pode não estar a ser efetivado em termos práticos no cenário judicial. É num argumento protecionista e paternalista que se pode colocar entraves à envolvência da criança e do jovem nos processos que lhe dizem respeito (Gonçalves \& Sani, 2013; Sani, 2013), visto que a imaturidade e vulnerabilidade das crianças têm sustentado a perspetiva dos adultos para o impedimento do exercício pleno dos direitos das crianças na sociedade, com o argumento que eles sabem melhor determinar os melhores interesses das crianças (Fernandes, 2009; Sani, 2013; Tomás, 2007). As conceções que os adultos têm sobre as crianças e sobre a infância repercutem na maneira com que as relações são estabelecidas entre estes dois grupos sociais. É frequente a infância estar associada a um período em que as crianças são consideradas física e psicologicamente imaturas, aliados ainda a uma incompetência social e ignorância cultural (Tomás, 2007) e por isso mesmo, necessitam de proteção (Fernandes, 2009; Sarmento \& Pinto, 1997). Esta visão reforça as desigualdades nos diálogos e nas relações de poder estabelecidos entre adultos e crianças (Tomás, 2007), abafando a "voz" da criança na 
sociedade. Assim, as crianças não são meramente recetores de intervenção e de medidas protetoras por parte dos adultos. Só considerando-as como atores sociais e cidadãos completos de direitos se poderá modificar as visões pré-estabelecidas sobre a infância (Sarmento \& Pinto, 1997; Tomás, 2012).

Esta população pode ser enredada nas malhas da justiça quando há casos de denúncia de abusos sexuais, de maus-tratos perpetrados pelos seus pais ou representantes legais, em casos de regulação do exercício das responsabilidades parentais em consequência do divórcio dos pais, ou em casos de delinquência juvenil, por exemplo. Mas a questão que se coloca é se o direito à expressão das crianças e dos jovens está a ser levado em consideração e a ser executado em termos práticos no sistema de justiça português. Será que as vozes dos "menores" são suficientemente audíveis junto dos magistrados que têm a decisão das suas vidas na mão?

\section{Participação da criança nos Tribunais e a tomada de decisão judicial}

O conflito de interesses entre o Estado, os direitos dos pais e os direitos das crianças tornam-se evidentes nas questões legais que surgem quando há desintegração ou quando existem disfuncionalidades no seio familiar, levando ao envolvimento das crianças nos enredos do sistema legal (Wiley, Bottoms, Steverson \& Oudekerk, 2006), sendo elas as mais afetadas pelas decisões tomadas nos cenários judiciais (Fanetti, O’Donohue, Fondren-Happel \& Daly, 2014). De acordo com estes autores, os tribunais têm a difícil tarefa de contrabalançar as necessidades e desejos da criança com a responsabilidade de assegurar que ela não voltará a ser vítima de abuso ou de negligência.
A audição e a participação das crianças nos processos judiciais que lhes dizem respeito podem permitir que estas sintam que as suas vozes foram consideradas (Hobbs et al., 2014; Parkinson, Cashmore \& Single, 2007), existindo manifesta vontade de estarem envolvidas nos processos judiciais (Cashmore \& Parkinson, 2009; Quas, Wallin, Horwitz, Davis \& Lyon, 2009). Alguns estudos (e.g., Weisz, Wingrove, Beal \& Faith-Slaker, 2011) indicam que as crianças que foram ouvidas nas audiências apresentam sentimentos mais positivos sobre os procedimentos dos tribunais, expressando níveis mais elevados de confiança no juiz, mais apreciações positivas da equidade da decisão do mesmo e mais conhecimento e compreensão sobre o seu caso. Todavia nem sempre essa participação é percecionada como eficaz pelas próprias crianças por sentirem que as suas vozes não são acreditadas nem ouvidas, desejando ter maior influência nas decisões judiciais tomadas (Block, Oran, Oran, Baumrind \& Goodman, 2010). Podem ainda colocar-se dúvidas sobre o comparecimento e a participação da criança poder resultar em consequências adversas para a mesma, levando-a a experimentar sentimentos negativos. Por exemplo, as crianças vítimas de maus-tratos podem sentir-se culpadas pela sua situação familiar ou pelas alegações instituídas no tribunal (Block et al., 2010; Quas et al., 2009) ou ainda porque não estão autorizadas a ter contacto com os seus pais (Hobbs et al., 2014). Certo é também que, se ouvidas de modo inadequado pode haver risco para a criança de uma vitimação secundária, frequentemente usada como argumento para apoiar a decisão para a não audição (Sani, 2013).

Diante do exposto, é crucial perceber como os decisores legais chegam às decisões. 
Há um debate persistente sobre a influência que as múltiplas fontes de informação, nomeadamente classificadas como "legais" e "extralegais", exercem nas decisões dos juízes (Martinek, 2010). Os estudos dessa área recaem sobre o efeito que a panóplia de informações de caráter não legal possui nas decisões dos juízes, pois consideram que estes fatores podem explicar a disparidade entre as decisões judiciais (Sacau \& Castro - Rodrigues, 2011).

Em Portugal, as decisões judiciais são tomadas pelos magistrados e na área da Psicologia há um interesse em estudar os quadros de referência que estes estabelecem na decisão judicial (Botelho \& Gonçalves, 2012). Partindo da conjetura de que um magistrado é um ator social, possuidor de um sistema de crenças, valores e experiências de vida (Parente \& Manita, 2010), a tomada de decisão judicial não constitui um processo que ocorre no "vazio", mas que deriva da combinação de diversos fatores, entre eles: as normas judiciais, leis constitucionais, ética, deontologia, política, educação, sociedade e características pessoais do juiz (Drobak \& North, 2008). Concluindo, esses fatores, conjugados com as particularidades inerentes a cada tipo de processo (Parente $\&$ Manita, 2010) e a cada caso específico, podem conduzir a desigualdades na tomada de decisões judiciais.

Outros autores (e.g., Arce, Fariña \& Seijo, 2005; Fariña, Arce \& Novo, 2002) sugerem que através da ancoragem, os juízes baseiam a formação da decisão judicial. A ancoragem trata-se de um processo de formação das representações sociais, através do qual os sujeitos recorrem à classificação e interpretação dos componentes da realidade social. A partir desse processo constroem uma rede de significações sobre os componentes, que posteriormente será assimilada cognitivamente no sistema de pensamento preexistente, transformando-o (Neto, 1998). Apesar de poder ser vantajosa, pois constitui uma estratégia facilitadora de economia cognitiva quando o sistema se depara com escassez de meios e de tempo ou por situação mais complexa, levando a limitações que poderão gerar erros de decisão (Fariña et al., 2002). Tendo em consideração que a ancoragem pode ter um papel preponderante na tomada de decisão judicial, é preocupante o facto de os juízes não terem em consideração que seus quadros de referência influenciam a decisão (Fariña et al., 2002; Arce et al., 2005).

Já na perspetiva de Wrightsman (1999) existem dois modelos para explicar a tomada de decisão judicial. De acordo com o modelo das atitudes, o magistrado toma a decisão tendo em consideração a perspetiva ideológica da Justiça. Assim sendo, as ideologias judiciais incutidas no magistrado, num passado momento, virão a influenciar a sua tomada de decisão no futuro. Por outro lado temos o modelo cognitivo, o qual se apresenta como resultado da cognição social em que o processo cognitivo é mediado pelo estímulo (a análise de novos casos e das provas endereçadas) e a resposta que se apresenta como a decisão do juiz. Esses dois modelos diferenciam-se pelo modo como as atitudes e os valores afetam a tomada de decisão. No modelo das atitudes, estas variáveis dirigem o comportamento a partir do qual as opiniões judiciais emergem. Já no modelo cognitivo a ênfase é colocada na perceção, ou seja, o processo das atitudes podem servir como filtros ou agitadores, não tendo um papel determinante no comportamento.

Outro esclarecimento sobre a forma como os magistrados produzem as suas decisões 
é a de Bartels (2010), que expõe os modelos top-down e bottom-up. Relativamente ao primeiro modelo (que tem por base a teoria), o indivíduo adota uma lógica de caráter dedutivo no qual as predisposições pessoais, perceções ou teorias predefinidas podem influenciar a forma como ele assimila os factos e as informações relevantes. Já no segundo modelo (que tem por base os dados), a vertente dedutiva é substituída por um processo mais ativo e indutivo, em que há maior cuidado no escrutínio de todas as informações, provas e factos, com a finalidade de uma tomada de decisão mais ponderada. Diríamos que esses não serão processos mutuamente exclusivos, pois muito embora possa haver um registo predominante de um tipo de abordagem, não é impossível produzir-se em alguma situação um registo diferente.

Pode-se assim concluir pela existência de várias explanações sobre tomada de decisão judicial, o que demonstra que deliberar não está confinado apenas às leis estipuladas, tratando-se antes de um processo dinâmico entre a aplicação da lei e um conjunto de fatores intrínsecos inerentes ao magistrado. Não obstante o predomínio ou a tendência do magistrado por um registo de trabalho fundado em fatores legais, é certamente possível, através da análise do seu discurso e de decisões que profere, extrair elementos que remetem para a existência de outros fatores. É este também o intuito do estudo exploratório a apresentar de seguida, cuja pertinência se justifica também pela importância social que subjaz ao (re)conhecimento de se há um exercício efetivo dos direitos da criança na justiça, trazida no caso pela opinião de quem toma decisões neste âmbito, descrevendo se o relato da criança influencia na tomada de decisão.
Este estudo pretende verificar a importância que os magistrados atribuem à audição das crianças e jovens envolvidos em processos judiciais e qual a sua influência na tomada de decisão. Para tal, será utilizada uma abordagem qualitativa de modo a recolher e compreender as representações que os participantes têm em relação à audição de criança no sistema de justiça, recorrendo à descrição das experiências e análise do significado que estes atribuem às práticas e aos acontecimentos que se viram confrontados no contexto judicial.

\section{Método}

\section{Participantes}

O estudo foi constituído por uma amostra intencional, não probabilística, de 12 magistrados, que exercessem ou tivessem exercido funções em Tribunais de Família e Menores. Desses participantes cinco são magistrados do Ministério Público $(41.6 \%)$ e sete judiciais $(58.3 \%)$, de ambos os sexos e com idades compreendidas entre os 43 e os 62 anos, sendo a média de idades de 51 anos $(D P=6.7)$. A maioria deste grupo é composta por participantes do sexo masculino $(n=7 ; 58 \%)$ comparativamente com o sexo feminino $(n=5 ; 42 \%)$. Os casados representam $92 \%$ do total da amostra, havendo apenas uma minoria divorciada $(8 \%)$. No que toca às habilitações académicas, a amostra é composta por licenciados em direito $(n=12)$, mas uma pequena percentagem refere ter realizado ou estar a realizar mestrados ou pós-graduações na área da justiça $(n=4 ; 25 \%)$. A média do tempo de exercício nas funções profissionais neste amostra é de 25 anos, enquanto que as funções exercidas na área de família e menores é de 8 anos. 
O processo de amostragem ficou concluído quando houve saturação teórica dos dados, ou seja, quando a informação recolhida não mais acrescentava novos dados aos já recolhidos (Coutinho, 2011; Fontanella et al., 2011).

\section{Instrumentos}

Para a recolha de dados recorreu-se à técnica de entrevista, tendo sido elaborado um guião semiestruturado e semidiretivo, ocorrendo a colocação das questões conforme as respostas e os assuntos apresentados e explorados por iniciativa do entrevistado. Este guião foi previamente testado, junto de dois magistrados, solicitando-se uma reflexão falada dos itens, seguido de uma resposta aos mesmos. Após a testagem do guião foram anotados todos os comentários e realizados pequenos ajustes de modo a que as questões demarcassem efetivamente os aspetos a serem explorados (Patton, 1990) e permitissem uma descrição com o maior grau de profundidade (Quivy \& Campenhoudt, 1992, 2008). O guião está organizado nos seguintes blocos temáticos: a) a audição da criança no sistema de justiça português; b) a importância da idade da criança para a audição; c) os procedimentos adotados quando realiza uma audição junto de uma criança ou de um jovem; d) tipo de informação retirada; e) quais os critérios/fatores que tem em consideração quando toma uma decisão num processo judicial que envolve uma criança ou um jovem; e f) qual a influência da audição da criança ou do jovem na tomada de decisão. Para o presente artigo serão exploradas duas das questões presentes nesse guião: $\mathrm{O}$ que pensa da audição de crianças ou jovens envolvidos no sistema de justiça? e Quais são os critérios que tem em consideração na tomada de decisão de um processo judicial que envolve uma criança?

\section{Procedimentos}

A realização deste estudo implicou previamente um pedido de autorização à Comissão de Ética da Universidade Fernando Pessoa. Após autorização, avançamos para a constituição da amostra tendo sido adotados dois procedimentos complementares. Num primeiro momento foram realizados contactos por correio eletrónico com dois magistrados, que segundo as investigadoras preenchiam os critérios de inclusão da amostra. Nesse email era solicitada a realização de uma entrevista, explicando-se os objetivos do estudo e o tempo aproximado de duração. Caso aceitassem, era então marcada a entrevista, na data e no local sugeridos pelos participantes. Efetuadas as primeiras entrevistas, o acesso aos participantes decorreu através da estratégia de bola de neve (Patton, 1990), ou seja, após o contacto com um magistrado, pedia-se a este que indicasse outros profissionais da área que estivessem disponíveis para a participação no estudo. A maior parte das entrevistas foi realizada nos gabinetes dos magistrados, o que apoiava a que estivessem mais predispostos a responder com naturalidade e à vontade.

Após a explicação dos objetivos e método utilizados no estudo foi solicitado aos magistrados o preenchimento do consentimento informado, o qual incluía o pedido para a gravação em áudio das entrevistas. As entrevistas gravadas foram guardadas num local seguro, até serem transcritas. Foram ainda reunidos alguns dados sociodemográficos dos participantes para posterior caracterização da amostra, garantindo-se o anonimato e a confidencialidade, sendo os dados recolhidos e usados apenas para fins científicos. 
Cada participante foi entrevistado individualmente e, no geral, as entrevistas tiveram duração média de vinte minutos, tendo após a gravação sido transcritas para posterior análise de conteúdo.

Os princípios orientadores para a interpretação das entrevistas regeram-se pela utilização de critérios de categorização, sendo as categorias principais previamente definidas (Bardin, 2009), atendendo às questões de partida enunciadas, e as subcategorias emergiram mais a partir do discurso dos magistrados, seguindo-se aqui o método da grounded analysis, que responde ao enquadramento teórico, epistemológico e empírico da Grounded Theory (Strauss \& Corbin, 1990, 2008). Esta metodologia assevera que através da recolha e análise sistemática e exigente dos dados, os investigadores ingressam para um processo dedutivo de produção de conhecimento (Fernandes \& Maia, 2001).

Assim, no tratamento da informação inicialmente avançamos através de um processo de categorização por caixas, dado que a organização dos dados seguiu de perto as questões de partida da investigação. Posteriormente, realizámos uma classificação analógica e progressiva do material empírico, utilizando-se um procedimento de codificação aberta de cada uma das 12 entrevistas, emergindo subcategorias em função dos conteúdos presentes nas respostas dos participantes.

No fim, obtida a codificação axial dos dados, foi examinada a relação entre as várias categorias e subcategorias, sendo que esta mesma análise decorreu através de um processo de triangulação por dois co-codificadores. Após a codificação independente foi realizado um processo de recodificação em diferentes momentos e por etapas até à constituição de um sistema de categorias definitivo. Por cada etapa, definida a partir dos objetivos traçados, era feita uma avaliação por meio de uma grelha do acordo vs desacordo na categorização pré-estruturada e da aberta. No final contabilizou-se o número de acordos face ao total de categorias, tendose obtido uma taxa de fiabilidade em torno dos $75 \%$.

A partir das análises dos discursos dos decisores legais sobressaíram as seguintes categorias centrais (tabela 1).

\section{Resultados}

Tomaremos a ordem de exibição das categorias e subcategorias no quadro para fazermos a apresentação dos dados, seguida de breve descrição, clarificada com alguns excertos dos discursos dos participantes, identificados pela letra P. A numeração associada pretende indicar a ordem das entrevistas realizadas, sendo que de P1 a P5 tratam-se de magistrados do ministério público e do P6 a P12 são magistrados judiciais.

\section{Importância da audição}

Relativamente à importância que é atribuída à audição das crianças e jovens no sistema de justiça, denotou-se unanimidade entre os magistrados $(n=12)$. No entanto, foram apontados fundamentos diversos para a realização dessa diligência, razão pela qual derivam desta categoria várias subcategorias, a saber: obrigatoriedade legal; melhor conhecimento da criança; apoio à decisão e auxílio à recolha de informação. 
Tabela 1

\section{Categorias e subcategorias resultantes da análise}

\begin{tabular}{|c|c|c|}
\hline Categorias & Subcategorias & Descrição das subcategorias \\
\hline \multirow[t]{4}{*}{$\begin{array}{l}\text { Importância } \\
\text { da audição }\end{array}$} & Obrigatoriedade legal & $\begin{array}{l}\text { Referência dos instrumentos jurídicos internaci- } \\
\text { onais e nacionais para evidenciar a obrigatorie- } \\
\text { dade da audição da criança. }\end{array}$ \\
\hline & $\begin{array}{l}\text { Melhor conhecimento da } \\
\text { criança }\end{array}$ & $\begin{array}{l}\text { A audição constitui um procedimento para co- } \\
\text { nhecer a criança que está por trás de cada proces- } \\
\text { so. }\end{array}$ \\
\hline & Apoio a decisão & $\begin{array}{l}\text { A audição da criança é uma forma de colaborar } \\
\text { no processo de tomada de decisão sobre os seus } \\
\text { projetos de vida. }\end{array}$ \\
\hline & $\begin{array}{l}\text { Auxílio à recolha de } \\
\text { informação }\end{array}$ & $\begin{array}{l}\text { Este procedimento auxilia na recolha de informa- } \\
\text { ções junto da criança. }\end{array}$ \\
\hline \multirow[t]{5}{*}{$\begin{array}{l}\text { Critérios na } \\
\text { tomada de } \\
\text { decisão }\end{array}$} & Superior interesse da criança & $\begin{array}{l}\text { Aquando da tomada de decisão, o superior inte- } \\
\text { resse da criança é o critério primordial pelo qual } \\
\text { estes se regem. }\end{array}$ \\
\hline & Outros critérios legais & $\begin{array}{l}\text { Enunciação de outros princípios legislativos ori- } \\
\text { entadores de intervenção relevantes para a toma- } \\
\text { da de decisão. }\end{array}$ \\
\hline & $\begin{array}{l}\text { Objetivos de cada tipo de } \\
\text { processo }\end{array}$ & $\begin{array}{l}\text { A tomada de decisão varia consoante o tipo e o } \\
\text { objetivo do processo. }\end{array}$ \\
\hline & Dados nos processos & $\begin{array}{l}\text { Os relatórios sociais, avaliações e outros docu- } \\
\text { mentos contidos nos processos são relevantes } \\
\text { para a tomada de decisão. }\end{array}$ \\
\hline & Opinião da criança & $\begin{array}{l}\text { Uma das variáveis mencionadas que auxiliam na } \\
\text { tomada de decisão. }\end{array}$ \\
\hline
\end{tabular}

Obrigatoriedade legal. A maioria da amostra $(n=11)$ faz referência a instrumentos jurídicos internacionais e nacionais para evidenciar a obrigatoriedade da audição da criança, para garantir o direito da expressão e opinião desta nos processos judiciais que lhe digam respeito.

A declaração dos direitos da criança já diz isso, desde 89 e cada vez mais os instrumentos de direito internacional, no Conselho de Europa, todos os instrumentos, diretivas, vão trabalhar no sentido de que as crianças têm o direito sagrado de se pronunciar sobre o seu próprio futuro (...) isso decorre da lei, decorre de todos os direitos internacio- nais (...) a criança tem que ser ouvida, ponto final, é a lei (P2).

Isso por imposição constitucional e por imposição, como sabe, de várias convenções institucionais, a magna delas é a convenção dos direitos da criança que dita que toda a criança deve ser ouvida (...) agora o importante em termos constitucionais e em termos jurídicos é que ela tenha a possibilidade de ser ouvida (P8).

Para além da própria lei, em muitos casos já instituir a obrigatoriedade da audição das crianças (...) para além da própria lei instituir, temos também os 
próprios regulamentos internacionais (...) na carta dos direitos da criança está expressamente consagrado o direito dele a ser ouvido (P12).

Melhor conhecimento da criança. Outra parte da amostra $(n=9)$ admite realizar a audição da criança e do jovem como uma forma de conhecer melhor o menor envolvido no processo.

(...) rapidamente percebi quais as razões deles, que eles evocavam para manter a situação que estava, em que viviam (...) percebemos as razões deles e percebemos a vontade deles (...) (P6).

Acho que pode fazer toda a diferença, é importante perceber-se, para se conhecer melhor a criança acho que é importante ouvi-la (...) conhecendo-a melhor, se poder decidir o que é mais adequado para ela (...), porque conhece-se melhor a realidade da criança $(\mathrm{P} 7)$.

É a situação vivencial até ao momento da decisão. (...) Portanto, aquilo que sucedeu na vida de uma criança e de um jovem até ao momento da decisão é um dos aspetos que tenho sempre em consideração (P11).

Às vezes, também vemos muito nos silêncios, também nos apercebemos que as crianças não estão bem, ou que estão manipuladas, ou que há uma pressão sobre elas, sobre o que devem ou não devem falar, sobre o que devem ou não devem dizer, como se devem ou não devem exprimir através de muitos silêncios (P12).

Apoio à decisão. Alguns magistrados $(n=4)$ enfatizam ainda a colaboração da criança no sentido de chegar a uma solução que vá ao encontro dos desejos e das necessidades dela. Assim, a audição da criança é uma forma de ela colaborar e contribuir para o processo de tomada de decisão sobre os seus projetos de vida.

Qualquer decisão que afete a criança pretende-se que tenha a colaboração dela, que tenha eficácia, que ela possa colaborar no seu projeto educativo (P1).

Ouvir a criança em questão para também perceber o que é que ela espera relativamente àquilo que irá ser decidido para ela dar o contributo dela, portanto, no sentido de ajudar também na busca da melhor solução para resolver a situação da criança (...) É sempre bom ouvir, mas claro que pode, dá sempre o seu contributo (P10).

Eu sempre entendi que a criança é o autor do seu próprio destino (...) a carta da vida dela escreve-se com ajudas, com impulso por parte dela (P8).

Auxílio à recolha de informação. Os participantes $(n=5)$ fazem referência à audição da criança ou do jovem como meio para obter informações junto da criança ou explicações sobre os factos que lhe são imputados.

É uma diligência importante não só porque é um momento importante de recolha de informação (P5).

(...) dão-nos informações muito reveladoras e novas que não estão no processo não é, e já tomei decisões um bocadinho assim, que aparentemente, se não ouvisse, os menores, nunca teria decidido (P6).

Nos tutelares educativos também é importante, para além de ser obrigatório ouvi-los nas audiências, quer na preliminar, quer no julgamento, porque eles 
têm que dizer não só se aceitam os factos que lhes vêm imputados, como se aceitam a medida que é proposta, e claro que isso é um peso importante. Se eles aceitarem e virmos que é razoável, é essa medida que se aplica, se eles, de todo, rejeitam os factos que lhes são imputados, quer a medida, temos que averiguar, produzir a prova, ajuizar se foi ele ou não que praticou os factos $\mathrm{e}$ depois a melhor medida (P9).

\section{Critérios na tomada de decisão}

Neste ponto, o que sobressai da análise são os critérios ou fatores que os magistrados têm em consideração quando tomam uma decisão em processos em que estão envolvidas crianças. As subcategorias emergentes foram: superior interesse da criança; outros critérios legais; objetivos de cada tipo de processo; dados nos processos e por fim, opinião da criança.

Superior interesse da criança. Nesta subcategoria, a maioria da amostra $(n=$ 10) alega que o principal critério em que baseiam a sua decisão é o superior interesse da criança. Contudo, estes magistrados afirmam que este é um conceito abstrato, vago e subjetivo.

Primeiro critério é saber qual é a decisão que melhor corresponde ao superior interesse dessa criança; é digamos o primeiro grande chapéu e o primeiro grande critério que se tem de tomar em consideração (...) qual é a solução que melhor corresponde ao seu interesse sem deixar de tomar em consideração obviamente os interesses de outros, pessoas que lhe são próximas (...) sempre que possível é o interesse da criança que prevalece (P5).

Para lhe citar a lei, um conceito abstrato que, muito aliás noticiado, é o supe- rior interesse da criança. (...) é esse o critério que o juiz tem sempre que tomar para decidir o que quer que seja relativamente a uma criança. (...) $\mathrm{O}$ superior interesse da criança é para aquela criança, naquele dado momento, aquilo que mais se adequa ao seu interesse. O superior interesse da criança não é o mesmo desta criança para a outra criança ou desta mesma criança, para ela mesmo, num momento diferente ou em circunstâncias diferentes (P12).

Outros critérios legais. Os entrevistados $(n=4)$ salientam também que há outros critérios legais importantes aquando da tomada de decisão, que vêm descritos na LPCJP (Lei No 147/99, de 1 de Setembro) como princípios orientadores de intervenção.

E depois há outros critérios, o critério da continuidade das relações afetivas, o critério da separação de irmão, da prevalência da família; quer dizer também encontrar preferencialmente soluções que mantenham a criança junto da família restrita ou alargada (...) todos eles são submissos ao critério base (P2).

Claro que no âmbito da LPP a lei diznos temos que aplicar, a lei diz-nos sempre que possível, o juiz deve procurar soluções dentro da família, só não havendo dentro da família, se não houver um pai, se não houver uma mãe, se não houver uma tia, se não houver um avô, então aí vamos para a confiança a pessoa idónea, não é, e em último caso a institucionalização (P10).

Objetivos de cada tipo de processo. Outro aspeto explorado apenas por um dos participantes é que a tomada de decisão varia consoante os objetivos de cada tipo de processo. 
Eu no tipo de processo (...) os objetivos perseguidos são diferentes, se se tratar de um processos tutelar educativo (...) é promover a educação por direito (...) um processo de promoção e proteção o que está em causa no fundo é (...) conseguir salvaguardar, digamos, a integridade física e psicológica do jovem ou da criança em questão retirando-a do contexto de perigo em que se encontra ou então mantendo um contexto familiar em que já a estava ajudando (...). Se tratar de um processo cível (...) é tratar distinguir e decidir qual será das soluções equacionadas em questão aquela que mais facilmente responda ao superior interesse do jovem (P4).

Dados nos processos. Nos processos judiciais estão anexados um conjunto de documentos (e.g., relatórios sociais, avaliações psicológicas, etc.) que contêm dados relativos ao caso e que, segundo alguns entrevistados $(n=2)$, são pertinentes quando tomam uma decisão.

Mas o que se toma, a globalidade da informação consistente no processo e que nos é transmitido por variadas formas, como lhe disse, relatórios sociais, exames periciais, provas testemunhais, provas documentais, de outro género. (...) Portanto, o que tribunal tem que aferir é: qual a melhor solução, qual é o melhor projeto de vida para a criança e encontrado o melhor projeto de vida para a criança, em face de todas as provas que são recolhidas no processo (P12).

Opinião da criança. Grande parte dos entrevistados $(n=9)$ menciona a audição da criança como um dos pontos que se dever considerar na tomada de decisão. A expressão e opinião das crianças sobre o que pensam relativamente ao que foi tra- zido a tribunal são consideradas pelos magistrados.

Mas, não sendo determinante o que ela diz é, a maioria das vezes, tão importante que condiciona praticamente todas as decisões que vamos tomar (...). Logo, o que ela disse, para o mais ou para o menos, é importante na decisão, muito importante, em todo o tipo de decisão (P1).

Depois é fundamental ela saber que a opinião dela e importante mas não é decisiva (...) acho relevante, que ela querendo diga o que ela pensa daquela situação, devem saber que aquilo que ela pensa foi considerado na decisão, e portanto, não foram uns tipos iluminados, que agora pensam que sabem da vida delas sem lhes dar qualquer tipo de oportunidade (...) a opinião da criança obviamente é um grande critério, todos eles são submissos ao critério base (P2).

A audição da criança, de alguma forma, também é valorado, mas a criança tem direito à audição sobre qualquer decisão que irá ser tomada sobre a sua própria vida, a criança tem o direito de audição (...). E portanto, sendo um dos fatores, que estão em linha de peso para a tomada de decisão (P12).

\section{Discussão dos resultados}

A análise efetuada aos discursos dos participantes teve como finalidade a resposta aos objetivos estipulados para esta investigação, com vistas a extrair as representações dos magistrados sobre a audição de crianças e jovens no sistema de justiça português.

A amostra é unânime quanto à importância da audição da criança e do jovem nos 
processos que lhes dizem respeito, fazendo muitas vezes menção aos instrumentos internacionais e nacionais sobre essa matéria. No sistema de justiça português, a importância atribuída a este procedimento na prática dos profissionais de justiça pode dever-se às constantes alterações jurídicas e legislativas realizadas por Portugal ao longo de várias décadas (Gonçalves \& Sani, 2013) e ainda à ratificação dos principais documentos internacionais sobre o direito das crianças e dos jovens, nomeadamente a Convenção sobre os Direitos da Criança, a Convenção Europeia para o Exercício dos Direitos da Criança, entre outros (e.g., Conselho da Europa, 2013; Unicef, 2004). O art $^{\circ} 12$ da Convenção sobre os Direitos da Criança (Unicef, 2004) é bem claro quanto ao direito de crianças e jovens expressarem a sua opinião sobre os assuntos que lhes dizem respeito nos processos judiciais (Fernandes, 2009; Sani, 2013; Tomás, 2011). Com essas medidas, Portugal pretende assim progredir e investir na promoção, proteção e participação infantil na área da justiça, levando a uma maior consciencialização e sensibilidade dos magistrados para o valor da audição.

A partir deste estudo constatou-se que a audição da criança e do jovem constitui uma das fontes de informação para os participantes, pois é uma forma de ter melhor conhecimento da criança, tendo a perspetiva dela sobre os assuntos que a levaram a tribunal, bem como uma forma colaborar no processo de tomada de decisão sobre os seus projetos de vida. $\mathrm{Na}$ perspetiva de Krinsky e Rodriguez (2006), para um decisor legal deliberar de forma responsável, precisa de todas as evidências disponíveis e uma das melhores fontes de informação é a criança.

Nesta investigação também se verificaram os critérios considerados pelos magistra- dos quando tomam uma decisão relativa a um processo que envolve uma criança ou um jovem. A Lei de Promoção e Proteção (LPP) de Crianças e Jovens em Perigo (Lei No 147/99, de 1 de Setembro) enfatiza um conjunto de princípios orientadores de intervenção, que são: o interesse superior da criança e do jovem; privacidade; intervenção precoce; intervenção mínima; proporcionalidade a atualidade; responsabilidade parental; prevalência da família; obrigatoriedade da informação; audição obrigatória e audição e subsidiariedade. $\mathrm{O}$ superior interesse da criança é o mais citado, mas também fazem alusão a outros critérios (e.g., existência de família). Desta forma, este conceito é vago e indeterminado, proporcionando aos entrevistados a adequação deste, da melhor forma, a cada criança e a cada situação específica (Bolieiro \& Guerra, 2009).

Perante a análise, os entrevistados parecem adotar preferencialmente o modelo bottom-up (Bartels, 2010) para deliberar, pois nos seus discursos declaram ter em conta todos os fatos, provas e informações relevantes em cada caso. A audição da criança conjugada com as demais informações incluídas em cada processo levam a uma decisão mais refletida. No que toca a outras fontes de informação, Botelho e Gonçalves (2012) concluíram que as periciais forenses são valoradas pelos magistrados quando tomam uma decisão. Denota-se ainda que é dado destaque à opinião da criança sobre os assuntos que lhe dizem respeito. Porém, é na consideração de todos estes componentes da realidade, que se constroem novos significados (Neto, 1998), capazes de transformar pensamentos e afetar decisões. A consideração de aspetos tão subjetivos como a maturidade, a impacto da experiência, as significações e sentimentos evidenciados pelos intervenientes trazem ao processo novos registos e a 
possibilidade de, mesmo no domínio de uma abordagem mais fundada nos dados, possa haver situações em que as predisposições pessoais sejam difíceis de afastar.

Uma pesquisa sobre a participação da criança nos tribunais mostrou que crianças querem ser ouvidas (Quas, Wallin, et al., 2009), porque sentem necessidade de ser reconhecidas, de ter uma oportunidade de dizer algo sobre assuntos importantes das suas vidas, até para que as decisões tomadas tenham subjacente o que elas disseram (e.g., Cashmore \& Parkinson, 2009; Parkinson et al., 2007). Esse envolvimento pode produzir na criança um sentimento mais positivo sobre os tribunais (Weisz et al., 2011), muito embora nem sempre estas crianças se sintam ouvidas (Block et al., 2010). A captação das representações das crianças sobre o processo de audição dos magistrados é então de especial relevo para a compreensão do envolvimento da criança na justiça, razão pela qual já no decurso deste estudo com magistrados está a ser conduzido um outro com crianças institucionalizadas e as suas representações quanto à audição pelos magistrados.

Não obstante a pertinência dos resultados, o estudo enfrenta algumas limitações. A metodologia utilizada não permite fazer generalizações para o universo do cenário judiciário quanto à audição da criança, mas apenas uma reflexão neste contexto particular. Houve também certa dificuldade em aceder à amostra, considerando os critérios de inclusão definidos (e.g., ser magistrado, ter exercido funções em tribunais especializados), assim como a limitada disponibilidade de tempo dos participantes (o que nos obrigou a deslocações várias no país). Importa ainda considerar entre as limitações a impossibilidade de controlar alguma desejabilidade social, que possa porventura estar camuflada nos discursos dos participantes. Por fim, apesar do nível bom de concordância intercodificadores as conclusões devem ser analisadas com reserva.

Para a realização de investigações futuras, seria interessante fazer uma observação no contexto sobre o modos operandi e os procedimentos adotados durante este tipo de diligências e contrabalançar com as representações já obtidas. Era importante ainda perceber as representações dos magistrados sobre a infância e a forma como essas representações tem repercussões no modo como se relacionam com as crianças. Por fim, sugere-se que haja mais investimento em pesquisas que se debrucem sobre a audição e participação das crianças no sistema de justiça, principalmente aquelas que estão numa posição de vulnerabilidade social (e.g., aquelas que se encontram em instituições de acolhimento, em regime de adoção, bem como os que estão indiciados por terem entrado em conflito com a lei) (Brito, Ayres \& Amendola, 2006).

\section{Conclusão}

Por se considerar que existe pouca literatura ou investigações em contexto nacional nesta área, a realização desta investigação visou compreender a abordagem da justiça relativamente à audição e à participação da criança e do jovem no sistema de justiça português. Assim, esta investigação surgiu com o intuito de compreender quais as representações dos decisores legais sobre a importância da audição da criança e do jovem e se a mesma consta como um dos critérios para a tomada de decisão. A partir dos dados obtidos, pôde-se constatar que os magistrados revelam dar valor à audição e à participação da criança nos processos judiciais e que a opinião e os pontos de vista desta sobre os assuntos que a levam 
a tribunal são uma importante fonte de informação para o processo de tomada de decisão.

Apesar dos melhoramentos ao nível do quadro legislativo, há ainda uma manifesta inadequação relativamente à atuação e funcionamento da justiça quanto às necessidades das crianças. A articulação entre a Psicologia e o Direito é uma mais-valia pois compõe uma junção importante para as tomadas de decisão (Gonçalves, 2010), como para todo o contexto judicial, de forma a colmatar as lacunas existentes no mesmo (Gonçalves \& Sani, 2015).

Devido às especificidades inerentes à condição infantojuvenil, torna-se necessário a garantia de uma abordagem mais especializada e direcionada às necessidades das crianças no contexto judicial. Os estudos demonstram que as crianças têm um escasso conhecimento relativamente aos conceitos legais (e.g. Flin, Stevenson \& Davies, 1989; Saywitz, Jaenicke \& Camparo, 1990) e processos judiciais, o que pode levar a crenças disfuncionais e a sentimentos negativos relativamente ao cenário jurídico (Block et al., 2010; Cooper, Wallin, Quas \& Lyon, 2010; Quas, Cooper, et al., 2009; Ribeiro, 2009). Fica patente em algumas investigações que as crianças revelam sentimentos negativos sobre a sua ida a tribunal, tais como ansiedade, medo, nervosismo e apreensão (Flin et al., 1989; Goodman et al., 1992). No sistema judicial português, há lacunas que podem desencadear a vitimação secundária das crianças vítimas de crime, tais como: a) a desadequação dos espaços; b) as exigências feitas às crianças sobre o processo-crime; c) as medidas de proteção insatisfatórias (Ribeiro, 2009); d) inadequação de alguns procedimentos judiciais; e) tendência para várias repetições do testemunho da criança sobre os eventos traumáticos (Manita \& Machado, 2012). Desta forma, a participação da criança no sistema de justiça pode resultar numa experiência traumatizante caso não sejam acauteladas as falhas no sistema jurídico relativamente a esta faixa etária.

Desta forma, Portugal deveria apostar em medidas fundamentais para a promoção e proteção dos direitos das crianças, como gabinetes de apoio e atendimento às vítimas nos tribunais (Gonçalves \& Sani, 2015), a criação de espaços destinados às crianças, programas de intervenção para a preparação da criança para a ida a tribunal (como já acontece noutros países, como por exemplo, o Canadá).

\section{Referências}

Arce, R., Fariña, F., \& Seijo, D. (2005). Razonamientos judiciales en procesos de separación. Psicothema, 17(1), 57-63.

Bardin, L. (2009). Análise do conteúdo. Lisboa: Edições 70.

Bartels, B. (2010). Top-down and bottom-up models of judicial reasoning. In D. Klein \& G. Mitchell (Eds), The psychology of judicial decision making (pp. 41-56). New York: Oxford University Press.

Block, S., Oran, H., Oran, D., Baumrind, N., \& Goodman, G. (2010). Abused and neglected children in court: Knowledge and attitudes. Child Abuse \& Neglect, 34, 659-670. 
Bolieiro, H. \& Guerra, P. (2009). A criança e a família - uma questão de direito(s). Visão prática dos principais institutos do direito da família e das crianças e jovens. Coimbra: Coimbra Editora.

Botelho, M. \& Gonçalves, R. (2012). Cada cabeça sua sentença: breve reflexão teórica acerca das decisões judiciais. Revista do Ministério Público, 130, 125-140.

Brito, L, Ayres, L., \& Amendola (2006). A escuta de crianças no sistema de justiça. Psicologia e Sociedade, 18(3), 68-78.

Bruñol, M. (1999). El principio del interés superior del niño en el marco de la Convención Internacional sobre los Derechos del Niño. Justicia y Derechos del Niño, 1, 45-62.

Carvallo, G. (2008). El principio del interés superior del niño y la Corte Interamericana de Derechos Humanos. Estudios Constitucionales, 6(1), 223-247.

Cashmore, J. \& Parkinson, P. (2009). Children's participation in family law disputes: The views of children, parents, lawyers and counselors. Family Matters, 82, 14-21.

Conselho da Europa (2013). Directrizes do comité de ministros do conselho da Europa sobre a justiça adaptada às crianças. Strasbourg: Council of Europe Publishing. Recuperado de

http://www.coe.int/t/dghl/standardsetting/childjustice/Source/GuidelinesChildFriendlyJu stice_PT.pdf

Cooper, A., Wallin, A. R., Quas, J., \& Lyon, T. (2010). Maltreated and nonmaltreated children's knowledge of the juvenile dependency court system. Child Maltreatment, 15(3), 255-260.

Couso, J. (2006). El niño como sujeto de derechos y la nueva justicia de familia. Interés superior del niño, autonomía progresiva y derecho a ser oído. Revista de Derechos del Niño, 3-4, 145-166.

Coutinho, C. P. (2011). Metodologia de investigação em ciências sociais e humanas: teoria e prática. Coimbra: Almedina.

Cunha, A. \& Fernandes, N. (2012). Participação infantil: a sua visibilidade a partir da análise de teses e dissertações em sociologia da infância. Em L. V. Dornelles \& N. Fernandes (Eds.), Perspetivas sociológicas e educacionais em estudos da criança: as marcas das dialogicidades luso-brasileiras (pp. 36-48). Braga: Centro de Investigação em Estudos da Criança, Universidade do Minho.

Drobak, J. N. \& North, D. C. (2008). Understanding judicial decision-making: The importance of constraints on non-rational deliberations. Journal of Law \& Policy, 26, 131-152.

Fanetti, M., O’Donohue, W. T., Fondren-Happel, R., \& Daly, K. N. (2014). Forensic child psychology: Working in the courts and clinic. New Jersey: John Wiley \& Sons.

Fariña, F., Arce, R., \& Novo, M. (2002). Heurístico de anclaje en las decisiones judiciales. Psicothema, 14(1), 39-45.

Fernandes, E. \& Maia, A. (2001). Grounded theory. Em M. Fernandes, M. Eugénia, \& L. Almeida (Eds.), Métodos e técnicas de avaliação: contributos para a prática e investigação psicológicas (pp. 49-76). Braga: Universidade do Minho. 
Fernandes, N. (2009). Infância, direitos e poder. Representações, práticas e poderes. Porto: Edições Afrontamento.

Flin, R., Stevenson, Y., \& Davies, G. (1989). Children's knowledge of court proceedings. British Journal of Psychology, 80, 285-297.

Fundo das Nações Unidas para a Infância, Unicef. (2004). A convenção sobre os direitos da criança. Recuperado de http://www.unicef.pt/docs/pdf_publicacoes/convencao_direitos_crianca2004.pdf

Fontanella, B., Luchesi, B., Saidel, M., Ricas, J., Turato, E., \& Melo, D. (2011). Amostragem em pesquisas qualitativas: proposta de procedimentos para constatar saturação teórica. Cadernos Saúde Pública, 27(2), 389-394.

Gabinete de Documentação e Direito Comparado (s.d.). Convenção europeia sobre o exercício dos direitos da criança. Recuperado de http://direitoshumanos.gddc.pt/3_3/IIIPAG3_3_10.htm

Gonçalves, R. (2010). Psicologia forense em Portugal: uma história de responsabilidades e desafios. Análise Psicológica, 1(28), 107-115.

Gonçalves, M. \& Sani, A. (2013). Instrumentos jurídicos de proteção às crianças: do passado ao presente. E-Cadernos CES, 20, 186-200.

Gonçalves, M. \& Sani, A. (2015). A participação da criança na justiça: estudo com crianças expostas à violência doméstica. Revista de Psicologia da Criança e do Adolescente. 6(1), 157-169.

Goodman, G. S., Taub, E. P., Jones, D. P., England, P., Port, L. K., Rudy, L., \& Prado, L. (1992). Testifying in criminal court: Emotional effects on child sexual assault victims. Monographs of the Society for Research in Child Development, 57(5), 1-142.

Guerrero, I. (2002). El principio del interés superior del niño en las situaciones de crisis familiar: una perspectiva comparada en el ámbito de la unión europea. Psicopatología Clínica, Legal y Forense, 2(3), 87-108.

Hobbs, S., Goodman, G., Block, S., Oran, D., Quas, J., Park, A., ... Baumrind, N. (2014). Child maltreatment victims' attitudes about appearing in dependency and criminal courts. Children and Youth Services Review, 44, 407- 416.

Krinsky, M. \& Rodriguez, J. (2006). Giving a voice to the voiceless: Enhancing youth participation in court proceedings. Nevada Law Journal, 6(3), 1302-1307. Retrieved from http://scholars.law.unlv.edu/cgi/viewcontent.cgi?article=1406\&context=nlj

Lansdown, G. (2011). Every child's right to be heard: A resource guide on the UN committee on the rights of the child general comment $N^{o}$ 12. London: Save the Children UK. Retrieved from http://www.unicef.org/french/adolescence/files/Every_Childs_Right_to_be_Heard.pdf

Manita, C. \& Machado, C. (2012). A psicologia forense em Portugal: novos rumos na consolidação da relação com o sistema de justiça. Análise Psicológica, 30(1-2), 15-32.

Martinek, W. (2010). Judges as members of small groups. In D. Klein \& G. Mitchell (Eds.), The psychology of judicial decision making (pp.73-84). New York: Oxford University Press. 
Neto, F. (1998). Psicologia social. Lisboa: Universidade Aberta.

Parente, C. \& Manita, C. (2010). Tomada de decisão judicial na regulação do exercício das responsabilidades parentais: estudo exploratório sobre algumas variáveis que a podem influenciar. Em C. Nogueira, I. Silva, L. Lima, A. T. Almeida, R. Cabecinhas, R. Gomes (...) M. C. Taveira (Eds.), Actas do VII Simpósio Nacional de Investigação em Psicologia, Portugal (pp. 3357-3367). Universidade do Minho, Braga.

Parkinson, P., Cashmore, J., \& Single, J. (2007). Parents' and children's views on talking to judges in parenting disputes in Australia. Legal Studies Research, 7(8), 1-37.

Patton, M. Q. (1990). Qualitative evaluation and research methods. Newbury Park, California: Sage Publication.

Quas, J. A., Cooper, A., \& Wandrey, L. (2009). Child victims in dependency court. In B. L. Bottoms, C. J. Najdowski, \& G. S. Goodman (Eds.), Children as victims, witnesses, and offenders (pp. 128-149). New York, NY: Guilford Press.

Quas, J. A., Wallin, A. R., Horwitz, B., Davis, E., \& Lyon, T. D. (2009). Maltreated children's understanding of and emotional reactions to dependency court involvement. Behavioral Sciences and the Law, 27, 97-117.

http://dx.doi.org/10.1002/bsl.836

Quivy, R. \& Campenhoudt, L. (2008). Manual de investigação em ciências sociais (5 $\left.{ }^{\mathrm{a}} \mathrm{Ed}.\right)$. Lisboa: Gravida. (Trabalho original publicado 1992).

Ribeiro, C. (2009). A criança na justiça: trajectórias e significados do processo judicial de crianças vítimas de abuso sexual intrafamiliar. Coimbra: Edições Almedina.

Sacau, A. \& Castro-Rodrigues, A. (2011). A cidadania e a (des)identificação dos cidadãos com a justiça - um contributo da psicologia. Antropológicas, 12, 32-37.

Sani, A. I. (2013). Reflexões sobre infância e os direitos da participação da criança no contexto da justiça. E-Cadernos CES, 20, 75-89.

Sarmento, M. J. \& Pinto, M. (1997). As crianças e a infância: definindo conceitos delimitando o campo. Em M. Pinto \& S. M. Jacinto (Eds.), As crianças contextos e identidades (pp. 7-30). Centro de Estudos da Criança: Editora Bezerra.

Saywitz, K., Jaenicke, C., \& Camparo, L. (1990). Children's knowledge of legal terminology. Law and Human Behavior, 14(6), 523-535.

Strauss, A. \& Corbin, J. (2008). Basics of qualitative research: Techniques and procedures for developing grounded theory $\left(3^{\mathrm{a}}\right.$ Ed.). Thousand Oaks: Sage Publications. (Trabalho original publicado 1990).

Tomás, C. (2007). Paradigmas, imagens e concepções da infância em sociedades mediatizadas. Media \& Jornalismo, 11, 119-134.

Tomás, C. (2011). 'Há muitos mundos no mundo'. Cosmopolitismo, participação e direitos da criança. Porto: Edições Afrontamento.

Tomás, C. (2012). Direitos da criança na sociedade portuguesa: qual o lugar da criança? Da Investigação às Práticas, 2(1), 118-129. 
Weisz, V., Wingrove, T., Beal, S., \& Faith-Slaker, A. (2011). Children's participation in foster care hearing. Child Abuse \& Neglect, 35, 267-272.

Wiley, T., Bottoms, B., Steverson, M., \& Oudekerk, B. (2006). A criança perante o sistema legal: dados da investigação psicológica. Em A. Fonseca, M. R. Simões, M. Simões, \& M. Pinho (Eds.), Psicologia forense (pp. 313-354). Coimbra: Edições Almedina.

Wrightsman, L. (1999). Judicial decision making: Is psychology relevant? In R. Roesch \& S. Fraser (Eds.), Perspectives in law e psychology (pp. 1-242). New York: Klumer Academic/ Plenum Publishers. 